\section{Una cálida presentación para un mejor futuro}

\section{A warm introduction for a better future}

En aras de continuar con el proceso de actualización y mejora del conocimiento en cada aspecto relacionado con la neumología y la cirugía de tórax, quiero presentarme ante todos: soy el doctor Elkin Enrique Llanos Sarmiento. En mi carácter de Presidente de la Asociación, pondré todo mi empeño para mejorar las condiciones de esta, con el fin de impulsar las actividades científicas y, por ende, el desarrollo de nuevo conocimiento en las áreas de neumología y cirugía de tórax en busca de efectuar una promoción de las condiciones de salud de la sociedad.

Para el cumplimiento de este objetivo tendré en cuenta varias actividades, tales como la mejora del proceso de gestión y desarrollo de la revista de la Asociación, la implementación de la plataforma en línea de la Asociación y futuros proyectos relacionados, la implementación de la plataforma del Consejo Colombiano de Acreditación y Recertificación Médica de Especialistas y Profesiones Afines (CAMEC) para la inscripción de los miembros que corresponda, el desarrollo del proceso de recertificación del Programa de recertificación Médica Voluntaria de la Asociación Colombiana de Neumología y Cirugía de Tórax (PReCoNTo) y, finalmente, mantenimiento y mejora de las actividades científico-académicas tradicionales, así como la implementación de nuevas alternativas importantes como el próximo congreso de cirugía de tórax.

Para llevar a cabo estas actividades y dar cumplimiento a las metas y objetivos, quiero comprometer a todos los capítulos, y por medio de ellos a todos los miembros antiguos y futuros de la Asociación, con el fin de generar una sinergia que permita facilitar la creación de un ambiente académico y, a través de esto, de un conocimiento basado en la discusión a partir del cual se mejoren aspectos relevantes en relación con los procedimientos, técnicas y medios dentro de las especialidades de la neumología y la cirugía de tórax. Me siento halagado de asumir este reto y de seguir trabajando en beneficio de la Asociación, de los miembros y de los demás actores involucrados en nuestros procesos.

Finalmente, quiero contar, como siempre, con la participación activa de todos ustedes en las actividades futuras a realizar.

Muchas gracias y éxitos para todos.

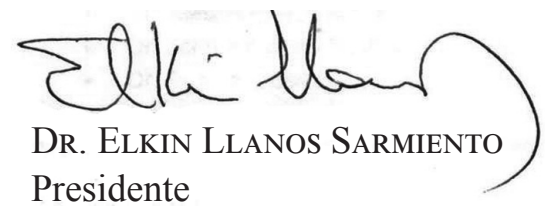

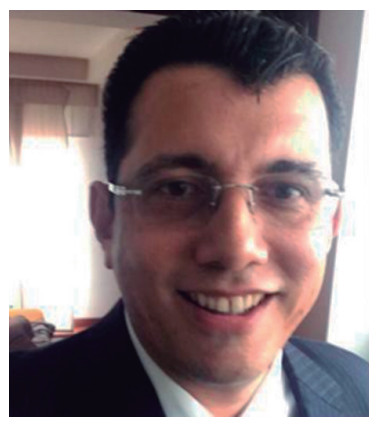

ELKIN LLANOS SARMIENTO, MD
Autor de Correspondencia:

Elkin Enrique Llanos Sarmiento, Presidente Asoneumocito. Cra. 7. ${ }^{\text {a }}$ Bis \# 12352; oficina 202.

Correo electrónico: presidente@asoneumocito.org

Recibido: 20/11/17. Aceptado: 02/12/17. 